\title{
INTERAÇÃO FAMÍLIA-CRIANÇA: POSSIBILIDADES DE NEGOCIAÇÃO NA CO-CONSTRUÇÃO DA ESCRITA *
}

\author{
Silmara C. D. Munhoz $\star \star$

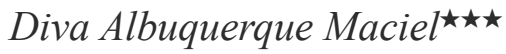

\begin{abstract}
RESUMO
A abordagem sociocultural construtivista destaca a relevância dos processos de negociação presentes nas interações família-criança em contexto de leitura e escrita para a constituição do leitor. Este artigo, parte de um amplo estudo, pretende identificar nas interações família-criança possibilidades de negociação e sua contribuição para a construção do significado do ler e escrever pela criança. O material analisado originou-se de uma situação estruturada realizada com alunos iniciantes do ensino fundamental de uma escola pública do DF e seus familiares. Participaram dos episódios videogravados e selecionados para este trabalho, duas meninas - ambas com sete anos de idade - e suas mães. Uma microanálise dos dados foi realizada, considerando-se os aspectos comunicativos e metacomunicativos das interações entre as díades. Nessas interações observouse divergências de objetivos que, por sua vez, conduziam a negociações positivas ou a impasses. Este aspecto faz refletir sobre a importância das qualidades das relações humanas para a co-construção da linguagem escrita.
\end{abstract}

Palavras-chave: Co-construção da linguagem escrita. Processo de negociação. Interações família-criança.

\section{INTERACTION FAMILY-CHILDREN: NEGOTIATION POSSIBILITIES IN THE CO-CONSTRUCTION OF THE WRITTEN}

\section{Abstract}

The sociocultural constructivist approach shows the relevance of the negotiation process lived in interactions child-family in context of reading and writing to constitution of the reader. This paper, part of a wider research, tries to identify in the interactions child-family, possibilities of negotiation and its contribution in the construction the meaning of reading and writing by the children. The analyzed subject was extracted of a situation applied to students of the first year of the elementary level of a public school in DF, and with their relatives. Two girls,

\footnotetext{
$\star$ Apoio Financeiro: $\mathrm{CNPq}$

$\star \star$ Doutoranda do Programa de Pós-Graduação em Psicologia da UFSC, da área de Concentração "Práticas Sociais e Constituição do Sujeito". Endereço: Fortium - Grupo Educacional. SGAS 909 Módulo 29 - Asa Sul - Brasília, DF. CEP: 70390-090.

E-mail: silmaracarina@gmail.com

$\star \star \star$ Professora Doutora, pesquisadora associada e faz parte do corpo docente do programa de PósGraduação em Desenvolvimento Humano e Saúde do PED/IP - UnB.
} 
both with seven years old, and their mothers, were selected and videotaped for this paper. A microanalysis of the data was made, considering the communicative and metacommunicative aspects of the participants interactions. Conflicts on the goal orientation of dyads were observed. These conflicts promoted positive negotiations or real impasses to joint construction of the written language.

Keyword: Co-construction of the written language. Negotiation process. Interactions family-child.

\section{INTRODUÇÃO}

A partir da segunda metade do século XX, acreditava-se que a hegemonia da escrita estivesse ameaçada pelo mundo imagético e virtual da mídia televisiva e, mais recentemente, da mídia eletrônica. Contudo, basta sair às ruas para observar a efervescência de signos gráficos que invadem o ambiente urbano, reafirmando o poder da escrita. Em outras palavras, a sociedade ainda é predominantemente grafocêntrica, e saber ler e escrever representa uma importante forma de poder (MACIEL, 1999; MACIEL; BARBATO; QUEIROZ, 2003; MASSINICAGLIARI; CAGLIARI, 2005).

O ser humano constitui-se na e pela relação que estabelece com o outro. Nesse processo, constrói significados, compartilhados ou não, sobre as atividades que desenvolve. Daí a importância de se buscar compreender as redes relacionais em que o sujeito está imerso. No que se refere à linguagem escrita, as interações que este mantém com o outro em atividades que envolvem o ler e o escrever, aqui compreendidos como uma prática histórico-cultural, assumem importância focal.

Ressalta-se que tais interações não se restringem àquelas vivenciadas no universo escolar, local responsável, na sociedade atual, pela sistematização do ensino-aprendizagem da língua escrita. Também as interações estabelecidas desde a mais tenra idade no seio familiar e os processos de negociação aí engendrados são de grande valor para a construção de uma relação significativa da criança com a linguagem escrita. Nesse contexto, arquitetado nos pressupostos teóricos da abordagem sociocultural construtivista, o presente trabalho propõe-se a identificar, nas interações família-criança vivenciadas em situações específicas de leitura e escrita, as possibilidades de negociação e sua contribuição para a construção do significado do ler e do escrever pela criança.

A abordagem co-construtivista do desenvolvimento humano, ou sociocultural construtivista - como essa perspectiva vem sendo nomeada pelo grupo de estudos do Labmis (Laboratório de Microgênese nas Interações Sociais) da Universidade de Brasília (BRANCO et al., 2004), representa uma saída, tanto teórica quanto metodológica, para a investigação dos processos interativos por meio dos quais a leitura e a escrita são construídas. Essa abordagem parte do ponto de vista sociogenético, de acordo com o qual todo processo psicológico humano é social por natureza. Embora as abordagens construtivistas e sociogenéticas sejam identificadas como historicamente distintas e inconciliáveis, observa-se hoje no 
discurso da psicologia do desenvolvimento um ativo movimento de busca de síntese dessas duas abordagens teóricas. Valsiner $(2001,2003)$ considera a necessidade de uma perspectiva teórica que possibilite defender a preservação do papel da pessoa ativa e que constrói seu mundo psicológico em constante relação com a realidade na qual se insere. Assim, o desenvolvimento humano é caracterizado pela construção conjunta do sistema psicológico da pessoa por si própria e, ao mesmo tempo, orientada por objetivos de "outros sociais".

Socialização é aqui conceituada como um processo de construção ativa em que a criança em desenvolvimento co-constrói, e, portanto, transforma os valores e conhecimentos transmitidos pela cultura, superando a herança de seus pais. Esta é uma perspectiva bidirecional de transmissão cultural, no sentido de que permite que se tome a cultura simultaneamente ao nível da unidade social ou coletiva e ao nível da pessoa. Isto é, segundo essa perspectiva, cada pessoa elabora a versão internalizada, e, portanto, própria, da cultura coletiva, o que também se constitui por meio da cultura pessoal.

Esta noção de transmissão cultural bidirecional é de fundamental importância para se compreender a co-construção da leitura e da escrita, na medida em que indica os processos por meio dos quais é possível pensar tanto a construção do novo quanto a singularidade do indivíduo. Além disso, cultura aqui é vista como um produto da construção semiótica e, portanto, sempre influenciada pela sugestão social. Ou seja, é por meio da ação conjunta da sugestão social e da participação ativa do sujeito no desenvolvimento de simbolizações personalísticas do objeto que o ser humano participa de seu desenvolvimento. Dentro desse contexto, a investigação dos processos interativos envolvidos na aprendizagem da linguagem escrita assume grande interesse.

Considerando-se que as funções psicológicas superiores, entre elas a linguagem, devem ser compreendidas levando-se em consideração a motivação social do indivíduo, Branco (2006, p. 143) define esta motivação como um sistema aberto de "orientações para crenças, valores e objetivos que levam às ações da pessoa em determinados contextos sócio-históricos-culturais". Tais orientações se originam e engendram novas interações entre os sujeitos, aspecto que permite que os indivíduos organizem seu próprio desenvolvimento. É importante salientar que essa orientação é dinâmica, flutuante e intensamente ligada ao contexto em que as ações ocorrem (BRANCO, 2006). As orientações para objetivos podem ser "convergentes" ou "divergentes". A divergência surge quando há incompatibilidade de objetivos dos participantes em interação. Nessa situação, pode ocorrer um processo de "negociação" que se define como o movimento da divergência para a convergência, ou seja, que faz emergir a compatibilidade e consistência na interação, e possibilita, assim, a construção ativa da intersubjetividade. Dessa forma, os desencontros e confrontos ocorridos em situações divergentes caracterizam-se como um rico e amplo campo de produção de sentidos. Ou seja, é nessas circunstâncias que se encontram possibilidades de negociar e estabelecer contato com a diversidade que o outro nos oferece, instaurando-se nesse processo 
um movimento que permite que os sujeitos envolvidos na relação construam um novo olhar e novos sentidos. Por sua vez, é nesse processo que se engendram transformações no modo de ser dos sujeitos que se relacionam.

Entretanto, vale ressaltar que o processo de negociação não se resume ao mero ato de um dos participantes em interação ceder aos seus objetivos, enquanto o outro se vê obrigado a abrir mão de sua crença. Na verdade, se há de fato negociação, o embate que ocorre entre os participantes nesse processo deve gerar condições para que ocorra uma re-significação dos sentidos que provocaram o confronto, engendrando mudanças no desenvolvimento de cada um dos envolvidos. Compreendido dessa forma, o processo de negociação caracteriza-se como uma estratégia fundamental no desenvolvimento humano, na medida em que possibilita ao sujeito ser co-participante do mesmo. Nesse processo, as metas de cada sujeito estão sempre sendo objeto de constante negociação e renegociação entre os participantes em interação, de maneira que tais orientações possam ser alteradas a qualquer momento, aspecto que caracteriza o desenvolvimento humano como indeterminado.

Dessa forma, o sujeito é definido como um ser em relação e que se desenvolve por meio dos processos de negociação e de produção de sentidos que vão constituindo os nós da ampla rede de sugestões sociais em que se encontra inserido. Nesse contexto, interações assumem vital relevância para o processo de co-construção da linguagem escrita, em busca de práticas que culminem em transformações na relação do sujeito com a realidade na qual se insere.

Sabe-se que a família, responsável pela socialização primária da criança, possui um papel central no seu desenvolvimento, uma vez que lhe compete, inicialmente, a transmissão de valores, crenças e costumes da cultura de que faz parte. Contudo, é importante ressaltar que, de acordo com a perspectiva teórica aqui adotada, a família promove, canaliza e cria constraints, isto é, um espaço psicológico que circunscreve o movimento da criança e, dessa forma, orienta o curso de seu desenvolvimento. No entanto, vale ressaltar que este espaço delimitado apenas oferece indícios da trajetória do desenvolvimento da criança, mas não o determina. Apesar da influência do contexto social mais amplo, a grande importância da família, especificamente, deve-se ao fato de esta exercer a função de uma espécie de filtro que vai selecionar e/ou regular as relações da criança em diferentes contextos, como, por exemplo, com quais crianças o filho poderá brincar; com qual idade e que instituição educacional a criança deverá freqüentar e, dessa forma, oferece-lhe um contexto próprio por meio de suas práticas culturais da vida diária. Práticas estas que vão-se constituindo em goal orientations, isto é, orientações para objetivo, por meio das quais a criança vai co-construindo uma cultura pessoal.

A relação família-cultura é bastante complexa, pois não se caracteriza pela mera transmissão cultural (crenças, valores, atitudes), uma vez que nem a família nem a criança recebem e interiorizam esses valores da maneira como lhes são "dados" culturalmente. Esses conhecimentos culturais são re-interpretados de modo bidirecional pelos participantes, de forma que da "cultura coletiva" 
constrói-se uma "cultura pessoal" (MACIEL; BRANCO; VALSINER, 2004). Quando o indivíduo re-elabora as mensagens que estão presentes ao seu redor, na verdade as transforma e, por meio da mediação semiótica, as internaliza. Dessa forma é que se tem a compreensão de que é por meio das relações estabelecidas com o outro, especialmente no seio da família, que cada indivíduo encontra condições de mudar a si mesmo e ao contexto no qual se insere. No presente estudo, considera-se a importância da família nas interações que buscam canalizar o processo de co-construção do significado da linguagem escrita pela criança. São aqui estudados momentos que revelam, nesse movimento interacional, a possibilidade de se instaurar negociações entre adulto-criança, em situação de leitura e escrita, com vistas a identificar a contribuição destas negociações para a constituição do leitor/escritor.

\section{MÉTODo}

O material aqui analisado originou-se de uma pesquisa mais ampla (MUNHOZ, 2003) que teve como foco as interações família-criança numa situação estruturada (SE). O estudo foi realizado em uma escola pública de $1^{\text {a }}$ fase do ensino fundamental - Escola Classe - do Plano Piloto de Brasília que atende a uma clientela de classe média baixa. Participaram do estudo original 15 díades formadas por crianças de uma turma de alfabetização ( $1^{\mathrm{a}}$ série) e o adulto responsável por auxiliá-las nos deveres escolares, em geral, as mães. A faixa etária dessas crianças era de 6 anos e 7 meses a 8 anos e 8 meses.

\section{Participantes}

Para o presente artigo, foram selecionadas duas dentre as 15 díades, as quais são constituídas por duas meninas de sete anos de idade e suas respectivas mães.

Os aspectos de ordem ética - garantia de sigilo e autorização para utilização da filmadora - foram rigorosamente respeitados durante toda a realização da pesquisa. Todos os participantes assinaram o Termo de Consentimento Livre e Esclarecido.

\section{Procedimentos de construÇão de dados}

Na biblioteca da escola foi organizada uma situação estruturada (SE) chamada de "Cantinho da Leitura e Escrita". No fundo da sala, sobre um tapete com almofadas, foram colocadas uma mesinha com duas cadeiras, uma poltrona e uma pequena estante. De forma acessível, encontravam-se sobre a mesa diversos materiais para escrita, e na estante, materiais de leitura como livros, gibis infantis, um jornal e duas revistas: uma de generalidades para adulto e outra infantil. Uma câmera de vídeo foi posicionada em um canto da sala, de modo a registrar as interações das díades ocorridas nesse ambiente.

Em horário previamente combinado, cada díade era convidada a utilizar esse "Cantinho". Mães e crianças ficavam sozinhas na sala e podiam escolher a atividade que desejassem realizar, em conjunto ou individualmente, com o 
material disponível. Também foram realizadas entrevistas com as mães e observações em sala de aula, com o intuito de conhecer os outros contextos em que o ler e o escrever se inserem.

\section{RESUltados E DiscusSão}

Uma vez que o objetivo do presente trabalho consiste em identificar, nas interações família-criança, momentos em que se aspira e/ou se instaura um processo de negociação frente às divergências de metas entre os sujeitos em situações que envolvem o ler e o escrever, foram selecionados, para o estudo que ora se delineia, dois episódios (A e B) ocorridos com as díades apresentadas. Tais episódios buscam evidenciar seqüências de eventos interativos que focalizam tentativas e/ou processos de negociação nas trocas dialógicas entre mães e filhos, durante atividades que envolviam leitura e escrita.

A partir de uma análise interpretativa das interações vivenciadas pelas díades foi possível observar situações em que havia divergências quanto aos objetivos dos participantes da díade, no tocante às atividades de ler e escrever.

Em busca de soluções frente às tensões originadas de tais divergências, mães e crianças encetavam um processo de negociação no qual ambos almejavam superar os conflitos gerados pela discrepância entre os objetivos, tornando possível a realização da atividade de modo que cada um pudesse usufruir desse momento. Nesse contexto de atividades referentes ao ler e ao escrever, observou-se um conflito na orientação para objetivos entre as crianças e suas mães. Enquanto as crianças estavam orientadas para a atividade gráfica do desenho, as mães claramente procuravam fazê-las ler e escrever de forma alfabética e ortográfica, reafirmando a importância de tal forma de escrita no atual cenário social. Com o propósito de facilitar a apresentação dos dados, em cada seqüência interacional os turnos de fala $[\mathrm{T}]$ estão numerados, de modo a permitir sua referência facilmente na análise.

\section{EPISÓdIo A - DíAde 1}

A criança do episódio A era a filha mais velha do casal, que tinha outro filho de 4 anos. Na entrevista, relatou que a filha apreciava muito ler livros da época em que ela e seu marido estudavam e escrever textos. O episódio a seguir ocorre no início da SE. Mãe e filha, que se encontram sozinhas na sala, sentam-se nas cadeiras, a mãe (M1) olha para a criança (C1) e indaga: 
Episódio A - Díade 1 (M1 e C1)

\begin{tabular}{|c|c|}
\hline MÃE (M2) & CRIANÇA (C2) \\
\hline $\begin{array}{l}\text { 1- "Então... se juntar: } x \text {, } \\
i, \text { c, a como é que fala?" }\end{array}$ & \\
\hline & $\begin{array}{l}\text { 2- "éeee..." pensa na resposta } \\
\text { "x..." (hesitante). }\end{array}$ \\
\hline $\begin{array}{l}\text { 3- "xi..." antecipa. Aponta } \\
\text { com o lápis para a próxima } \\
\text { letra }\end{array}$ & \\
\hline $\begin{array}{l}\text { 5- Balança a cabeça } \\
\text { negativamente apesar do } \\
\text { acerto da criança } \\
\text { (referindo-se à letra c), } \\
\text { denotando } \\
\text { Completa: "a ... cê, a ... } \\
\text { xica!" }\end{array}$ & $\begin{array}{l}\text { 4- "cê..." (hesitante - C2 se } \\
\text { empolga muito) }\end{array}$ \\
\hline & 6- Repete: "xica!" \\
\hline $\begin{array}{l}\text { 7- "Tem que aprender a } \\
\text { juntar as letrinhas..." }\end{array}$ & \\
\hline & $\begin{array}{l}\text { 8- Interrompe e muda de } \\
\text { assunto: "Faz a xícara aqui!" } \\
\text { aponta para o papel. Completa, } \\
\text { olhando para M2, em tom } \\
\text { desafiador: "Não sabe, não?" }\end{array}$ \\
\hline $\begin{array}{l}\text { 9- "Sei". Aceita o desafio } \\
\text { e escreve no papel a } \\
\text { palavra xícara. }\end{array}$ & \\
\hline & $\begin{array}{l}\text { 10- Observa M2 atentamente. } \\
\text { Depois que ela termina, c2 } \\
\text { sorri e diz (em tom de } \\
\text { correção): } \\
\text { "Nãão! Faz o desenho!" Levanta } \\
\text { as mãos. }\end{array}$ \\
\hline
\end{tabular}


Nesse episódio, observou-se que o objetivo de M1 não era apenas que a filha lesse e escrevesse, mas que tais atividades fossem realizadas de acordo com as normas institucionais de aprendizagem da escrita, isto é, como se escreve na escola. Dessa forma, sugeriu à filha uma atividade de leitura e escrita compatível com as normas acadêmicas tradicionais, orientando-a a iniciar a escrita com um cabeçalho, atividade que exigia da criança organização, localização no tempo e espaço, memória, mas sempre de forma a priorizar a escrita normatizadora. Considerando esse tipo de relação com a escrita é que M1 parece desconsiderar a maneira e o conteúdo da atividade de formar frases, proposta pela filha [T2].

Assim, inicialmente, parecia que ambas compartilhavam do mesmo objetivo - escrever. Contudo, notou-se que divergiam quanto ao conteúdo e à forma de realizar a atividade escrita. Ao propor a escrita de frases [T2] a criança metacomunicou, através do seu sorriso e pela expressão facial, que possuía satisfação em realizar uma atividade de sua escolha, na qual teria condições de criar com esta ferramenta, distanciando-se da escrita que comumente faz parte do seu cotidiano escolar. Além do episódio aqui apresentado, outros momentos também revelaram essa dissonância entre mãe e filha a respeito do desenvolvimento de uma atividade escrita. Por exemplo, sempre que $\mathrm{C} 1$ apresentava o mesmo comportamento - citando frases inusitadas e sorrindo, a mãe chamava-lhe a atenção, como no caso em que diz: "Pare $\mathrm{C}$, isto é coisa séria".

Diante da divergência nas orientações para objetivos [T5] M1 sugeriu à filha que, além de fazer um desenho, também escrevesse uma história para acompanhá-lo. Dessa forma, instaura-se um processo de negociação no qual a mãe não despreza o interesse da filha pelo desenho, mas motiva-a a complementar a atividade de modo que venha a alcançar seus próprios objetivos, isto é, que a criança realize a escrita alfabética. Assim, a negociação possibilita à díade uma re-significação dos objetivos iniciais dos sujeitos, e a atividade a ser desenvolvida atende a novos objetivos - a mãe compreende que o desenho faz parte da atividade e a criança que uma escrita normativa deva acompanhar o desenho.

Nesse caso, o processo de negociação possibilita a criação de novas estratégias na resolução do embate gerado pela divergência de orientações entre as díades. Sempre orientada por objetivos que evidenciem a escrita de forma normalizada segundo a escola, no turno [T8] M1 sugeriu à filha que pegasse um livro, com o intuito de que este a ajudasse a criar, mesmo a criança não tendo demonstrado qualquer dificuldade para inventar uma história. A estratégia utilizada pela mãe consistiu numa sugestão, em forma de pergunta, que dava à criança condições de participar do processo de negociação, e resolver o impasse entre seus objetivos - desenhar - e os de sua mãe - escrever. Novamente, notou-se uma re-significação dos objetivos iniciais de cada sujeito, e a construção de novas metas que parecem ser um acordo entre a díade de forma que se preservem os objetivos de ambos, gerando uma satisfação recíproca num movimento de cons- 
trução de novas possibilidades em relação à linguagem escrita. Esse aspecto revela a flexibilidade existente nas metas para objetivos dos sujeitos em interação, isto é, as intenções não são fixas e imutáveis, elas se constroem e re-constroem na intersubjetividade.

No entanto, $o$ ato de comunicação não expressa apenas a informação do assunto de que se trata, mas transcende este aspecto e oferece indícios da natureza do relacionamento interpessoal. Assim, por meio do que se pode definir como metacomunicação ou a comunicação da comunicação, isto é, gestos, tom de voz, olhar, evidencia-se o aspecto qualitativo do relacionamento (TACCA; BRANCO, 2003; TACCA, 2006). O aspecto metacomunicativo na interação entre mãe e filha, nesse episódio, pode ser observado pelo tom de empolgação de M1 ao propor que junto com o desenho a criança escrevesse uma história. M1 comportou-se como se tivesse realizado uma grande descoberta, a possibilidade de uma atividade mais completa com desenho e escrita alfabética. Ficou explícito que C1 contagiou-se por esta "empolgação", ou novidade, demonstrando interesse em realizar a atividade. Pode-se dizer que, nesse processo de negociação, a díade conseguiu encontrar uma solução para a dissonância de objetivos, uma vez que esta foi superada.

Notou-se, ainda, que, ao propor um conjunto de atividades mais complexas (desenho, leitura e texto escrito) do que inicialmente a criança havia-se prontificado a fazer - apenas desenhar -, M1 não titubeou quanto à capacidade da filha de realizá-la. Demonstrou acreditar que a criança seria capaz de desenvolver a atividade, embora bem mais complexa do que inicialmente se propunha. Por sua vez, a própria criança apresentava uma postura de satisfação e competência em relação à capacidade de ler e escrever, pois não hesitou em aceitar as sugestões da mãe. A análise de situações como estas revelam a importância da mediação do outro no processo de construção de sentidos acerca de atividades tipicamente humanas, tal como a linguagem escrita. Em outras palavras, a relevância do outro como mediador no processo de apropriação dos bens culturais.

\section{EPISÓdio B - DÍADE 2}

A criança do episódio B era filha única e morava somente com a mãe que era formada em contabilidade. No início da SE a menina optou por desenhar enquanto sua mãe preparava um "deverzinho" para a filha realizar. Quando M2 termina, C2 interrompe sua atividade de desenho para responder as questões do exercício feito pela mãe. Observe o episódio a seguir: 
Silmara C. D. Munhoz \& Diva Albuquerque Maciel

Episódio B - DíAde 2 (M2 E C2)

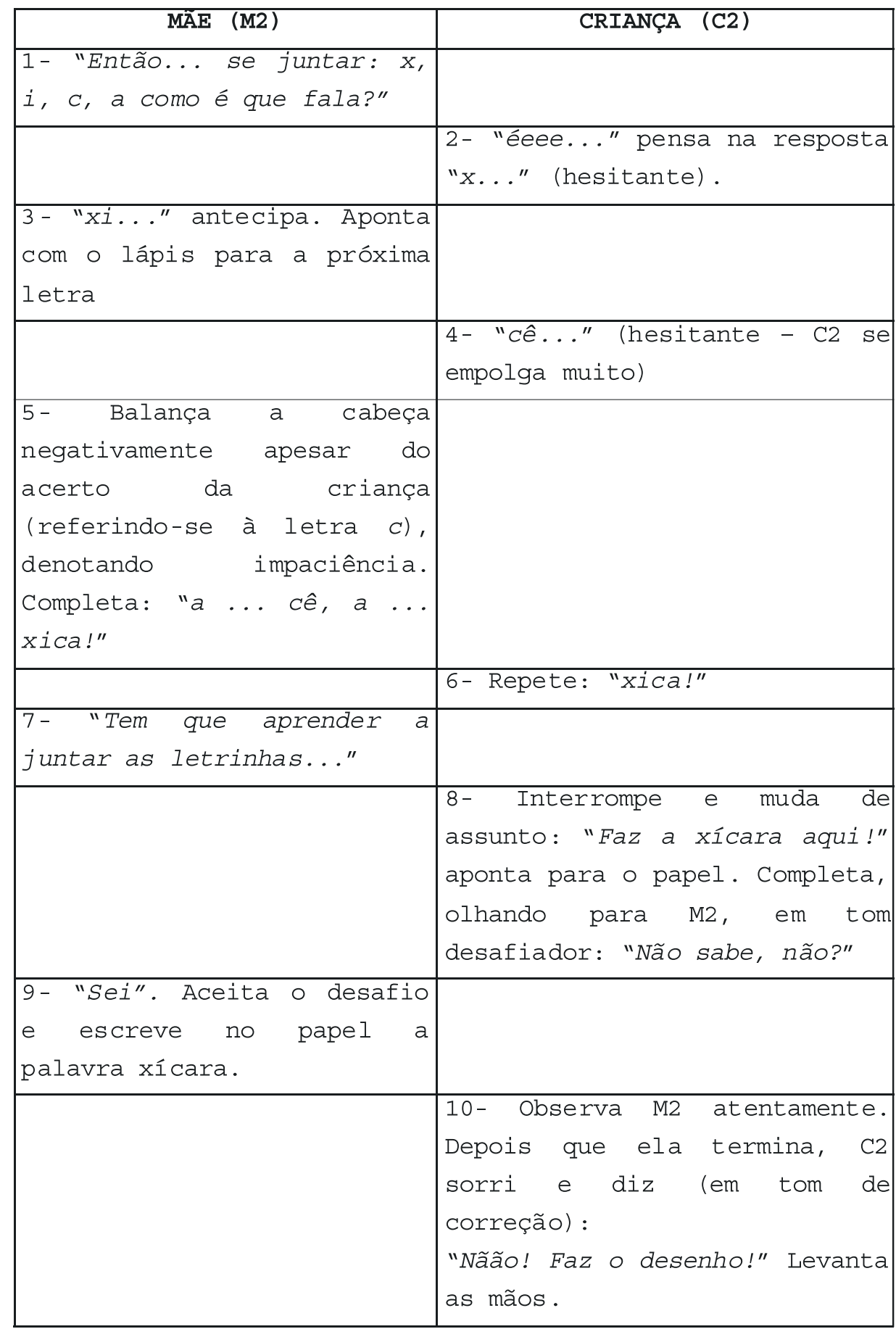


Interação família-criança: possibilidades de negociação na co-construção da escrita

\begin{tabular}{|c|c|}
\hline $\begin{array}{l}\text { 11- "Ah! O desenho..." } \\
\text { (fala como se estivesse } \\
\text { surpresa). Depois começa a } \\
\text { desenhar a xícara. }\end{array}$ & \\
\hline $\begin{array}{l}\text { 13- Enquanto desenha } \\
\text { comenta tranqüilo) } \\
\text { "Tem que aprender a juntar } \\
\text { as letrinhas..." }\end{array}$ & $\begin{array}{l}\text { 14- Interrompe novamente: "Eu } \\
\text { quero ir com um, dois, } \\
\text { três..!" sugere ler números em } \\
\text { vez do texto (tom choroso). }\end{array}$ \\
\hline $\begin{array}{l}\text { 15- Mostra o desenho da } \\
\text { xícara para a filha: "Viu?" }\end{array}$ & $\begin{array}{l}\text { 16- "Um, dois, três..." repete } \\
\text { enquanto observa o desenho. }\end{array}$ \\
\hline $\begin{array}{l}\text { 17- Aceita a sugestão, } \\
\text { escreve os números na folha } \\
\text { e pergunta: "Até que número } \\
\text { tem aqui?" }\end{array}$ & 18- "Oito!" \\
\hline 19- "Então conta a..." & \\
\hline $\begin{array}{l}\text { 21- Acompanha apontando com } \\
\text { um lápis e depois diz: } \\
\text { "escreve aqui: ma-mãe". }\end{array}$ & $\begin{array}{l}\text { 20- Lê os números "Um, dois, } \\
\text { três, quatro, cinco, seis, } \\
\text { sete, oito." }\end{array}$ \\
\hline
\end{tabular}


No caso dessa díade a mãe iniciou a SE com uma atividade voltada para seus objetivos, sem consultar a filha sobre o que poderiam fazer, demonstrando não achar necessária a participação da criança nas tomadas de decisões em situações que envolviam a linguagem escrita, atribuindo a esta uma condição passiva. Nesse contexto, $\mathrm{C} 2$ percebe que há divergência entre os objetivos de sua mãe e os seus próprios. Então a criança demonstra a intenção de negociar para que não tenha de abdicar de seu objetivo inicial - desenhar.

No turno [T8] a criança propõe, a fim de resgatar sua meta, uma atividade que seja condizente com a mesma - solicita à mãe que faça um desenho. Dessa forma, busca recuperar a atividade de desenhar, que foi trocada pela leitura de palavras do exercício que sua mãe preparou. Quando $\mathrm{C} 2$ pede à mãe que faça "... a xícara", esta, que continua centrada em seus objetivos, escreve a palavra "xícara", em vez de desenhar. Mesmo quando aceita desenhar M2 não abandona seus objetivos, comentando enquanto desenha: "Tem que aprender a juntar as letrinhas...".

Notou-se aqui, uma dificuldade de M2-C2 em negociar uma solução que atendesse a objetivos comuns ou mesmo que possibilitasse a construção de novas metas para a atividade. Talvez, por perceber o quanto M2 mantinha-se firme em seus objetivos - ler e escrever - e, vislumbrando a impossibilidade de mudança de atividade, $\mathrm{C} 2$ renunciou ao desenho e propôs outra atividade, agora que viesse ao encontro dos objetivos de sua mãe - a leitura de números [T16]. Nesse momento, $\mathrm{C} 2$ obteve sucesso no que se pode definir como processo de negociação, pois houve uma re-significação de suas metas, de forma que trocou o desenho pela escrita, mas a escrita de números. O seu entusiasmo e insistência ao alvitrar a nova atividade revelaram que esta the era mais agradável e possível que a anterior.

Contudo, M2 não aderiu completamente ao processo de negociação, pois, ao aceitar a proposta da filha, realiza a atividade de maneira muito breve e imediatamente retoma suas metas iniciando uma atividade que exigisse a escrita alfabética [T21].

Apesar de a criança ter dado início a uma negociação quanto à atividade que seria desenvolvida, observou-se que o adulto, mesmo abrindo uma breve concessão, não se engajou num processo de discussão e de novas possibilidades a respeito da atividade que realizaria com a filha. Talvez essa dificuldade em travarem um espaço de discussão e reflexão se deva ao fato constatado de que nas interações dessa díade sempre era reservado o lugar "do não saber" a um dos sujeitos. Este aspecto pode ser confirmado pela ocorrência da inversão de papéis, quando a criança questionou se a mãe não sabia fazer um desenho [T8]. E como se quem tivesse que realizar a atividade fosse identificado como aquele que "não sabe", enquanto quem tem o poder de solicitá-la é o detentor do saber. Muitas vezes tais características podem ser notadas em ambientes institucionais, nos quais o professor é o "sabe tudo" e a criança o ser que precisa ser "moldado", fato que será possível por meio do conhecimento que o "outro" tem a transmitir. No que se 
refere à língua escrita esse fator é bastante evidente no cotidiano, uma vez que ao sujeito alfabetizado e escolarizado é conferida uma condição especial, de sujeito do conhecimento, o que é negado ao sujeito analfabeto.

Notou-se nesta díade uma interação na qual o saber da criança foi ignorado, visto que em nenhum momento foi conferido a este "outro" a credibilidade de que fosse capaz de propor e desenvolver uma atividade de maneira autônoma e satisfatória.

\section{CONSIDERAÇÕES FINAIS}

Foi possível observar, no decorrer dos episódios apresentados, que as interações entre famílias e crianças em situações que envolviam o ler e escrever eram caracterizadas por um mister de mediações pedagógicas e cotidianas, pois, como sabemos, as relações pedagógicas fundamentam-se na intencionalidade e na sistematicidade. Já nas relações cotidianas não há uma intencionalidade do ensino, isto é, nesse tipo de relação não se tem uma consciência imediata do processo de ensino-aprendizagem. De acordo com Rocha (2005, p. 42) nas mediações cotidianas "em raros momentos, ambos, crianças e adultos, se dão conta da diferença da elaboração cognitiva existente entre eles". Talvez por estarem inseridas num contexto escolar, essas mães sentiram-se impelidas a agirem com seus filhos de forma mais próxima possível a uma mediação que poderíamos denominar de pedagógica. Tal aspecto eliminava, nesta interação, qualquer possibilidade de espontaneidade da criança ou, pelo menos, qualquer ação que pudesse se distanciar de uma intencionalidade de utilizar convencionalmente (ou academicamente) o ler e o escrever. Assim, foi possível observar que as interações mãe-criança em situações que envolvem linguagem escrita aparecem impregnadas de valores acadêmicos da escola tradicional, de intencionalidades e sistematizações que interferem na qualidade dessas interações.

Nesse contexto, a preocupação com a qualidade das interações interpessoais parecia estar num segundo plano, fato que dificultava a compreensão do funcionamento intersubjetivo como um processo que tem início com a regulação do outro e que visa assumir, via processo de negociação, um "caráter de partilha, suporte e harmonia" (GÓES, 1995, p. 27). Quanto à assimetria que caracterizava as interações em alguns episódios, pôde-se notar que é na própria dinâmica dos processos interativos que esta se institui, pois o outro atribui a seu parceiro um lugar de maior ou menor saber e este, por sua vez, encarrega-se de assumir ou não este lugar. Dessa forma, é possível que nas interações família-criança, num contexto que engloba a linguagem escrita, ocorram trocas dialógicas nas quais a participação do sujeito no processo de construção de conhecimento seja reconhecida, valorizada e incentivada. As palavras utilizadas pelos adultos revelam às crianças significados estáveis e incorporados pelo meio social no qual vivem. Nota-se que o processo de significação ocorre no campo da intersubjetividade, que é compreendido como espaço de encontro, de confronto e de negociação entre as significações de cada sujeito (privado) em busca de um lugar comum de 
produção de sentidos (PINO, 1993). E são esses novos sentidos (singulares), que consistem numa re-significação dos sentidos já apropriados, e outros sentidos (compartilhados) que serão desenvolvidos.

Ao estudar as interações família-criança é de suma importância situar o fenômeno em seu contexto social, histórico e cultural, considerar os sujeitos envolvidos como ativos, construtivos e transformadores, recíprocos e simultâneos, constituintes de uma totalidade. Assim, faz-se necessário compreender os (des)encontros e as possibilidades de negociações que ocorrem na interação com o outro. Nesse contexto, as crises familiares devem ser entendidas como momentos importantes de desenvolvimento e não apenas como denotação de fracasso e desorganização familiar, uma vez que a crise pode não somente trazer problemas, mas, principalmente, soluções (HOFFMAN, 2001). São nos momentos de acontecimentos significativos, que fazem parte do processo de transformação, que os membros da família devem aprender a negociar conceitos e atitudes, e refletir sobre a situação que vivenciam. O momento em que o filho ingressa na escola para ser alfabetizado é considerado como um desses eventos importantes, pois essa nova condição é capaz de provocar mudanças nas interações estabelecidas entre as crianças e seus familiares.

No que diz respeito à aprendizagem da língua escrita, as crenças e valores da família em relação a tais atividades podem interferir na relação dos pais com a criança no momento da alfabetização, gerando conseqüências positivas e/ou negativas para o processo. Dessa forma, é conhecida a importância de valorizar e respeitar a produção da criança em relação à leitura/escrita e, para tanto, é preciso que o adulto não se prenda apenas às questões técnicas, mas que também reconheça a espontaneidade da criança. Atitudes do outro mais experiente em relação ao aprendiz, tais como, aceitar seu estilo literário, dar-lhe autonomia para escrever, apreciar a atividade realizada, fazem com que a criança se sinta capaz, aumentando sua auto-estima, além de fazer com que ela se aproprie de atividades consideradas essenciais para seu desenvolvimento. Assim, a própria criança identifica um espaço no qual pode negociar seus objetivos com o outro e, então, criar condições que impulsionem seu desenvolvimento.

Uma vez que os diferentes lugares sociais ocupados pelos interlocutores viabilizam diversas formas de olhar, de apreender e (re)apreender a linguagem escrita, propiciando a emergência de novos sentidos relacionados ao ler e ao escrever, reconhece-se a necessidade de pessoas, fora do ambiente escolar, enfatizarem o caráter social e comunicativo da escrita, criando um contexto de apoio a este processo de aprendizagem. 


\section{REFERÊNCIAS}

BRANCO, A. U. et al. A sociocultural constructivist approach to metacommunication in child development. In: BRANCO, A. U.; VALSINER, J. (Ed.) Communication and meta communication human development. Greenwich: IAP, 2004. p. 03-31.

BRANCO, A. U. Crenças e práticas culturais: co-construção e ontogênese de valores sociais. Revista Pro-Posições, Campinas, v.11, n.7, p.139-155, 2006.

GÓES, M. C. R. de. A construção de conhecimentos: examinando o papel do outro nos processos de significação. Temas em psicologia, São Paulo, v.2, p.2329, 1995.

HOFFMAN, L. O ciclo de vida familiar e a mudança descontínua. In: CARTER, B; McGOLDRICK, M. (Org.). As mudanças no ciclo de vida familiar: uma estrutura para a terapia familiar. Porto Alegre: Artmed, 2001. p. 84-96.

MACIEL, D. A. A co-construção da subjetividade no processo de aquisição da leitura e da escrita. In: PAZ, M. G. T.; TAMAYO. A. (Org.). Escola, saúde e trabalho: estudos psicológicos. Brasília: Universidade de Brasília, 1999. p. 4170 .

MACIEL, D. A.; BARBATO, S. B.; QUEIROZ, N. L. Fundamentos teóricos e metodológicos da escrita da língua e da língua escrita. Brasília: SESI, v. 1, 2003.

MACIEL,D. A.; BRANCO,A.; VALSINER, J. Bidirectional process of knowledge construction in teacher-student transaction. In: BRANCO, A. U.; VALSINER, J. (Ed.). Communication and metacommunication in human development. Greenwich - CT: Information Age, 2004. v.1, p.109-125.

MASSINI-CAGLIARI, G.; CAGLIARI, L. C. Diante das letras: a escrita na alfabetização. Campinas: Mercado de letras, 2005.

MUNHOZ, S. C. D. Processo de alfabetização: uma análise das interações família-criança numa situação estruturada. 2003. Dissertação (Mestrado)-Universidade de Brasília, Brasília, 2003.

PINO, A. Processos de significação e a constituição do sujeito. Temas em Psicologia, São Paulo, v. 1, n. 1, p. 17-24, 1993.

ROCHA, M. S. P. Não brinco mais: a (des)construção do brincar no cotidiano educacional. São Geraldo Ijuí, RS: Unijuí, 2005. 
Silmara C. D. Munhoz \& Diva Albuquerque Maciel

TACCA, M. C. (Org.) Estratégias pedagógicas: conceituação e desdobramentos com o foco nas relações professor-aluno. In: . Aprendizagem e trabalho pedagógico. Campinas: Alínea, 2006. p. 45-68.

TACCA, M. C.; BRANCO, A. U. Comunicación y metacomunicación en situaciones de enseñanza y aprendizaje. Revista de Psicologia, San Marcos, Peru, v.2, n.7, p.127-145, 2003.

VALSINER, J. Comparative study of human cultural development. Madrid: Fundación Infancia y Aprendizaje, 2001.

. Sensuality and sense: Cultural construction of the human nature. Human $\overline{\text { Affairs, Bratislava, v.13, p. 151-162, } 2003 .}$

Recebido em: julho de 2007

Aceito em: março de 2008 